International Journal of Methods in Psychiatric Research

Int. J. Methods Psychiatr. Res. 22(4): 267-275 (2013)

Published online in Wiley Online Library

(wileyonlinelibrary.com) DOI: 10.1002/mpr.1401

\title{
Design of the Army Study to Assess Risk and Resilience in Servicemembers (Army STARRS)
}

RONALD C. KESSLER, ${ }^{1}$ LISA J. COLPE, ${ }^{2}$ CAROL S. FULLERTON ${ }^{3}$ NANCY GEBLER, ${ }^{4}$ JAMES A. NAIFEH, ${ }^{3}$ MATTHEW K. NOCK,${ }^{5}$ NANCY A. SAMPSON,${ }^{1}{ }^{\text {MICHAEL SCHOENBAUM, }}{ }^{2}$ ALAN M. ZASLAVSKY,${ }^{1}$ MURRAY B. STEIN, ${ }^{6,7}$ ROBERT J. URSANO ${ }^{3}$ \& STEVEN G. HEERINGA ${ }^{4}$

1 Department of Health Care Policy, Harvard Medical School, Boston, MA, USA

2 National Institute of Mental Health, Bethesda, MD, USA

3 Center for the Study of Traumatic Stress, Department of Psychiatry, Uniformed Services, University School of Medicine, Bethesda, MD, USA

4 Institute for Social Research, University of Michigan, Ann Arbor, MI, USA

5 Department of Psychology, Harvard University, Cambridge, MA, USA

6 Departments of Psychiatry and Family and Preventive Medicine, University of California San Diego, La Jolla, CA, USA

7 VA San Diego Healthcare System, San Diego, CA, USA

\section{Key words}

Suicide, mental disorders, US Army, epidemiologic research design, design effects, sample bias, sample weights, survey design efficiency, survey sampling

\section{Correspondence}

Ronald C. Kessler, Department of Health Care Policy, Harvard Medical School, Boston, MA, USA Telephone (+1) 617-4323587 Fax (+1) 617-432-3588 Email: NCS@ hcp.med. harvard.edu

Received 10 July 2013; accepted 15 July 2013

\section{Abstract}

The Army Study to Assess Risk and Resilience in Servicemembers (Army STARRS) is a multi-component epidemiological and neurobiological study designed to generate actionable evidence-based recommendations to reduce US Army suicides and increase basic knowledge about the determinants of suicidality. This report presents an overview of the designs of the six components of the Army STARRS. These include: an integrated analysis of the Historical Administrative Data Study (HADS) designed to provide data on significant administrative predictors of suicides among the more than 1.6 million soldiers on active duty in 2004-2009; retrospective case-control studies of suicide attempts and fatalities; separate large-scale cross-sectional studies of new soldiers (i.e. those just beginning Basic Combat Training [BCT], who completed self-administered questionnaires [SAQs] and neurocognitive tests and provided blood samples) and soldiers exclusive of those in BCT (who completed SAQs); a pre-post deployment study of soldiers in three Brigade Combat Teams about to deploy to Afghanistan (who completed SAQs and provided blood samples) followed multiple times after returning from deployment; and a platform for following up Army STARRS participants who have returned to civilian life. Department of Defense/Army administrative data records are linked with SAQ data to examine prospective associations between self-reports and subsequent suicidality. The presentation closes with a discussion of the methodological advantages of cross-component coordination. Copyright (c) 2013 John Wiley \& Sons, Ltd. 


\section{Introduction}

Suicide is the second leading cause of death among 25 to 44 year olds in the United States, claiming over 30,000 lives annually (Centers for Disease Control, 2005). For every completed suicide there are an estimated eight to 25 failed attempts (Goldsmith et al., 2002). In 1999 the US Surgeon General issued a "call to action" on suicide prevention, saying "the nation must address suicide as a significant problem," and recommending enhanced "research to understand risk and protective factors." The US military also identified suicide as a major concern at around the same time and created several initiatives, including a successful Air Force Suicide Prevention Program (afspp.afms.mil). However, in contrast to the suicide rate in the United States remaining fairly level over the recent past, the suicide rate in the US Army doubled between 2003 and 2008 and has continued to rise since then.

Historically, the suicide rate in the US military has been below that in the civilian population, but it has climbed steadily since the beginning of the Iraq and Afghanistan conflicts to the point where suicide is now the second leading cause of death behind combat deaths (Armed Forces Health Surveillance Center, 2012) and has exceeded demographically matched civilian rates since 2008 (Kuehn, 2009). In fiscal year 2009, there were 160 recorded suicides in the Army. Of those, 79\% were among soldiers who had deployed only once or had not deployed at all. Additionally, $60 \%$ of suicides were among first-term soldiers (http://www. army.mil/article/43038/army-releases-report-on-suicide-high -risk-behavior/). The rise in US Army suicides has persisted despite substantial efforts to publicize and encourage use of mental health services. Although many intervention programs are underway, success will require a better understanding of specific risk and protective factors in Army service. The profile associated with traditional individual risk factors (e.g. age, gender, presence of mental illness) may not generalize to Army personnel, all of whom are employed, selected for good health, and have health care available at no cost. Furthermore, the risk profile among military personnel might vary during different phases of duty and mission. Changing accession demographics (e.g. the number of new recruits with General Educational Development (GED) versus high school graduation, the number with conduct waivers) may also affect suicide risk, as suggested in a recent Institute of Medicine (IOM) report (Committee on Youth, 2006). Changes in barriers to care, both physical barriers (e.g. time and access to care) and community barriers (e.g. stigma, operational tempo, unit cohesion, leadership support), are also possible factors. More intangible risk and protective factors associated with war, such as increased feelings of patriotism and loyalty to one's unit might also be involved. Textured research on these and related issues is needed to identify modifiable risk and protective factors for suicidal behaviors and inform effective suicide risk and prevention strategies among Army servicemen and women.

The Department of the Army responded to these trends in 2008 by entering into an agreement with the National Institute of Mental Health (NIMH) to fund the Army Study to Assess Risk and Resilience in Servicemembers (Army STARRS; http://www.armystarrs.org), a multicomponent epidemiological and neurobiological study of risk and resilience factors for suicidality and its psychopathological correlates among Army personnel (Insel and McHugh, ). The two overarching goals of Army STARRS are: to evaluate hypotheses about modifiable risk and resilience factors for suicidality that could be used to target effective preventive interventions for Army suicides; and to expand basic scientific understanding of psychosocial and neurobiological risk and resilience factors for suicidal behaviors and their psychopathological correlates. The Army STARRS samples could also be used as baselines for intervention implementations and evaluations in the future.

Army STARRS is supported under a Cooperative Agreement (U01) between NIMH and a consortia of scientific collaborators at the Uniformed Services University of the Health Sciences (USUHS; PI: Robert Ursano), the University of California San Diego (PI: Murray Stein), Harvard Medical School (Site PI: Ronald Kessler), and the University of Michigan (Site PI: Steven Heeringa) through the Henry M. Jackson Foundation. Additional U01 collaborating scientists and consultants come from the NIMH (Lisa Colpe; Michael Schoenbaum) and the Army (Kenneth Cox; Steven Cersovsky). The Army STARRS includes a number of coordinated component studies designed to facilitate non-experimental hypothesis generation and testing, intervention targeting, and intervention evaluation.

The first of these initiated by Army STARRS collaborators examined historical data in an integrated data system created by combining information obtained from a number of Army and Department of Defense (DoD) administrative databases on all soldiers who served in the Army between 2004 and 2009. Retrospective case-control studies of fatal suicides and non-fatal suicide attempts were then designed to provide preliminary quantitative data on risk and resilience factors as well as to create an opportunity to obtain qualitative data to help generate new hypotheses. A series of major multi-mode self-report surveys were then launched that included neurocognitive and genetic data linked both retrospectively and prospectively to 
administrative data systems so as to examine patterns of association over time between risk-resilience factors and subsequent suicidal behaviors. Targeted sub-studies of high-risk soldiers and settings are now being planned that use these survey samples as sampling frames. Early component studies were designed to provide input into later component studies and subsequent interventions.

The current report presents a broad overview of the designs of these component Army STARRS studies. These studies were designed to create a coordinated whole to facilitate non-experimental hypothesis generation and testing, intervention targeting, and intervention evaluation. The individual study designs are for the most part conventional, but their coordination creates unique strengths. We discuss the synergistic effects of cross-component coordination after describing the individual studies.

\section{Army STARRS component studies}

\section{The Historical Administrative Data Study (HADS)}

The Army and DoD maintain over 200 different administrative data systems dealing with such diverse issues as certifications of training (Army Training and Requirements Resource System [ATRRS]), medical records (the Medical Data Repository [MDR] system), casualty reporting (Defense Manpower Data Center [DMDC/CASUALTY]), and, importantly for our purposes, suicidal behaviors (DoD Suicide Event Report [DoDSER] system). While prior to the initiation of Army STARRS special-purpose efforts had been made to integrate some of these data systems, we felt that a great deal more could be learned about risk and resilience factors for suicides by linking the DoDSER with some of the other systems. We consequently established the Army STARRS Historical Administrative Data Study (HADS), an integrated administrative data file containing key elements from 38 different Army and DoD data systems for the over 1.6 million soldiers (Regular Army, Army Reserve, and National Guard) on active duty at some time during calendar years 2004-2009. The Army subsequently expanded the integrated data files to be continually updated for purposes of use in targeting future interventions. Analyses of the 2004-2009 HADS data are allowing Army STARRS collaborators to examine time trends in suicides, other types of deaths, and non-fatal injuries (suicidal and others) as well as to study a wide range of predictors of those outcomes. These analyses are being carried out for the most part using discrete-time survival analyses (Singer and Willett, 2003) with person-month the unit of analysis based on the roughly 51.1 million person-months in this data array (37.0 million Regular Army, 5.3 million activated Army Reserve, 8.8 million activated Army National Guard).
Given the rarity of the outcomes under study, we are analyzing reduced samples consisting of all person-months with the outcomes of interest and a probability sub-sample of control person-months weighted by the inverse of their probability of selection and using a logistic link function to estimate coefficients.

In addition, individual-level data from the Army/DoD administrative data systems used to build the HADS are being linked to Army STARRS surveys for all consenting participants. Administrative data linked to the Army STARRS survey samples described later are allowing information from retrospective (to the surveys) administrative data, survey data, and, for some samples, neurocognitive and genetic data to be integrated to predict subsequent (prospective) outcomes identifiable in administrative records.

\section{Soldier Health Outcomes Studies A and B (SHOS-A/B)}

The Soldier Health Outcome Studies (SHOS) are retrospective case-control studies of soldiers who made nonfatal suicide attempts (SHOS-A) or were suicide fatalities (SHOS-B). While producing less definitive data than prospective studies on the predictors of suicidal behaviors, retrospective case-control studies like SHOS-A/B are useful because they provide rapid preliminary data on potentially important risk and resilience factors that can subsequently be evaluated more definitively in prospective naturalistic and intervention studies (Schlesselman, 1982).

SHOS-A cases are recruited from all patients in psychiatric inpatient units in five participating tertiary care medical facilities (Walter Reed National Military Medical Center, Washington, DC; Fort Bragg, NC; Fort Stewart, GA; Fort Lewis, WA; and Fort Hood, TX) who were admitted because of suicide attempts beginning November 2011. Cases provide written informed consent and then complete the same self-report survey as in our major survey of Army personnel (the All-Army Study [AAS], which is described later in this report), allowing case-control analyses to be carried out using all respondents from that survey as controls. In addition, a propensity score weight (Rosenbaum and Rubin, 1983) was developed based on case-control analysis of the first SHOS-A cases compared to AAS respondents to select a sub-sample of Regular Army AAS respondents as controls for more in-depth assessment, including an expanded version of the neurocognitive test battery used in the New Soldier Study (NSS) and collection of blood samples. Qualitative interviews based on the principles of reason analysis (Strauss, 1987) are also being administered to SHOS-A cases in an effort to uncover information about critical junctures in the progression to 
attempts. We anticipate a final SHOS-A sample of 150 cases and 300 group-matched controls.

SHOS-B cases are selected by attempting to interview the next of kin and Army supervisors of all soldiers who committed suicide (as recorded in the DoDSER system) beginning March 2012 plus a group-matched sample of controls. As with SHOS-A, controls are being selected from Regular Army AAS respondents based on a propensity score weight (Rosenbaum and Rubin, 1983), but in this case the weight was developed based on analysis of the HADS (total Army) sample using predictors of suicide found in administrative records. As in SHOS-A, a qualitative component is included in SHOS-B to help uncover information about critical junctures in the progression to suicide. Hypotheses generated from analysis of these qualitative data are being evaluated prospectively whenever possible by expanding the assessments in the NSS and AAS. We anticipate a final SHOS-B sample of 150 cases and 300 group-matched controls.

\section{The New Soldier Study (NSS)}

Between 140,000 and 190,000 new soldiers enter the US Army each year, including those in the Regular Army (about half of enlistees), the US Army Reserve (USAR), and the US Army National Guard (USANG). The majority of these new soldiers begin their active duty by going through three months of Basic Combat Training (BCT), the main exceptions being those who enter the Army as officers and those who enter the USAR or USANG after leaving the Regular Army. One of the Army STARRS component studies is the NSS, a study that attempted to assess over 57,000 of these new soldiers in the two days after their arrival to report for BCT. NSS respondents were selected from three Army installations that provide BCT (Fort Benning, GA; Fort Jackson, SC; and Fort Leonard Wood, MO) with sample sizes proportional to the relative sizes of the cohorts across these sites. Continuous sampling throughout calendar years 2011-2012 was used to account for the fact that the composition of new soldiers changes across the year due to an influx of recent high school graduates in the summer and fall.

The NSS included group administration of a two-part self-administered questionnaire (SAQ) and neurocognitive tests along with the collection of blood samples obtained as part of a physical examination given to all new soldiers prior to the beginning of BCT. The contents of the neurocognitive tests are described in a series of reports in preparation. All these data were collected in Reception Battalion (RECBN), the period typically lasting several days when new soldiers are processed (physical exams; immunizations; eye exams; issuance of uniforms and, as needed, special stress-resistant eyeglasses; completion of various forms) before beginning BCT. A new RECBN cohort typically enters on the same day each week throughout the year, but breaks for holidays.

Army STARRS was assigned an auditorium that could hold between 200 and 300 people using laptops for SAQ self-administration at the RECBN site on each BCT installation. Each week, the Army Point-Of-Contact (POC) at each RECBN site selected a sample of new soldiers equal to the number of seats in the auditorium to attend the Army STARRS informed consent session. Army STARRS worked with the POCs to prevent systematic bias in selection procedures. Thirty-minute informed consent sessions explained study purposes, procedures, and protections against breach of confidentiality (separation of identifying information from survey and neurocognitive data; assignment of a study ID with linkage to identifying information maintained securely by the University of Michigan data collection team; contractual agreement that identifying information will not be provided to the Army; protocols to report only aggregate results and coarsen public use datasets to minimize risk of individual identification), emphasize the voluntary nature of participation (including the right to withdraw consent at a future date), and answer questions before seeking informed consent.

Written informed consent was then obtained from volunteers. Although not necessary for SAQ participation, all NSS respondents were additionally asked for consent to link their Army/DoD administrative records to their NSS responses and to participate in to-be-determined longitudinal follow-up data collections. Identifying information (name, birthday, Social Security number (SSN) for record linkage; telephone number, email, secondary contact information for longitudinal follow-up) was collected from consenting respondents separately from the SAQ and never merged with de-identified NSS data. These recruitment, consent, and data protection procedures were approved by the Human Subjects Committees of the Uniformed Services University of the Health Sciences for the Henry M. Jackson Foundation (the primary grantee), the Institute for Social Research at the University of Michigan (the organization implementing STARRS data collection), and all other collaborating organizations.

Blood samples were then obtained from volunteers as part of the RECBN physical examination. This is in addition to the normal blood samples taken from new soldiers during the reception phase of BCT. New soldiers participating in Army STARRS and consenting to provide a blood sample had one additional vial of blood drawn for Army STARRS. SAQ and neurocognitive test data were obtained in two 90-minute group-administered data 
collection sessions over two successive days. Individuallevel Army/DoD administrative data were subsequently linked to the de-identified individual-level NSS data for the subsample of NSS participants who provided written informed consent for this linkage. Sample sizes, response rates, weighting, and design effects are described in a separate report (Kessler et al., 2013).

\section{The All-Army Study (AAS)}

The NSS focuses on a very small proportion of active duty soldiers; those about to enter BCT. Between 737,000 and 757,000 US Army soldiers have been on active duty at any point in time since the inception of Army STARRS data collection in early 2011 (576,000-581,000 Regular Army and 161,000-176,000 activated USAR or USANG), with only $8400-12,200$ of these soldiers in BCT at any point in time during the same period. The AAS is a cross-sectional SAQ survey carried out throughout 2011-2012 in quarterly samples of active duty Army personnel exclusive of those in BCT or in Afghanistan. Unlike NSS, no neurocognitive test data or genetic data are collected in the AAS. In addition, the AAS SAQ is considerably shorter than the NSS SAQ (one 90-minute administration session in AAS compared to two in NSS).

The quarterly AAS replicates in Q1-2 2011 were representative of all soldiers stationed in the continental United States, while those in the remaining quarters added soldiers stationed elsewhere in the world other than a combat theater. Each quarterly replicate consisted of a stratified (by Army Command and location) probability sample of Army units (or, for large units, sub-units) selected without replacement with probabilities proportional to authorized unit strength from a sample frame of Unit Identification Codes to yield a representative time-space sample. The frame excluded civilian-only units and units of fewer than 30 soldiers (representing less than $2 \%$ of all Army personnel).

In addition to these quarterly replicates, the AAS was augmented to increase coverage in two ways. First, it was administered in Q2-3 2012 to a probability sample of soldiers stationed in Afghanistan who were surveyed in group-administered sessions while they were passing through Kuwait either leaving for or returning from their mid-tour leave. Unlike other AAS respondents, those stationed in Afghanistan were surveyed as individuals rather than as units, as individuals leave their units for mid-tour leave. It should be noted that mid-tour leave, despite the name, did not all occur in the middle of the deployed soldier's tour in Afghanistan but rather at random times between the second and second to last months of deployment, guaranteeing that the AAS was administered at relatively random times other than at the very beginning or very end of deployment.

Second, the AAS was administered in 2012-2013 to a supplemental sample of activated USAR and USANG units in the continental United States either just before or just after deployment to Afghanistan in order to correct for the fact that these kinds of units were excluded from the Regular Army AAS sample frame.

All personnel in each selected AAS unit (or sub-unit) were targeted for a group-administrated SAQ survey and were ordered to report to a group informed consent session similar to those described earlier for the NSS. The AAS respondents stationed in Afghanistan, in comparison, were selected using methods similar to those in the NSS (i.e. POCs selected a number of soldiers equal to the number that could be accommodated by the Army STARRS group administration setting to participate in the informed consent session). In each case, an informed consent presentation similar to that in NSS was groupadministered to explain study purposes, procedures, and confidentiality protections, emphasize the voluntary nature of participation, and answer questions. Written informed consent was then obtained. As in the NSS, AAS respondents were additionally asked for consent to link their Army/DoD administrative records to their survey responses and to participate in to-be-determined longitudinal follow-up data collections. Identifying information (name, birthday, SSN for record linkage; telephone number, email, secondary contact information for longitudinal follow-up) was collected from consenting respondents separately from the survey and never merged with de-identified survey data. As with the NSS, these recruitment, consent, and data protection procedures were approved by the Human Subjects Committees of all collaborating organizations. Sample sizes, response rates, weighting, and design effects are described in a separate report (Kessler et al., 2013).

\section{The Pre-Post Deployment Study (PPDS)}

NSS and AAS respondents are being tracked longitudinally through their administrative records, however outcomes are limited to those that are administratively recorded, such as suicide fatalities, non-fatal suicide attempts sufficiently severe to come to the attention of the military healthcare system, and mental disorders treated in the military healthcare system. A great many outcomes of interest will be missed by these administrative records, such as suicidal ideation and plans and onsets of mental disorders known to be powerful risk factors for suicides. In order to 
address this problem, a number of targeted follow-up surveys are planned in the future; two of these are being implemented currently. The larger of these two is the PrePost Deployment Study (PPDS), a four-wave panel survey that collected baseline data (SAQ and blood samples) in Q1 2012 shortly before deployment to Afghanistan from 9421 soldiers in three Brigade Combat Teams. Follow-up data collections are scheduled for these same respondents three times after they return from deployment: within one month of their return (T1; SAQ and blood samples), two months after this first post-return assessment (T2; SAQ), and six months after the second post-return assessment (T3; web-based SAQ augmented with telephone interviews for SAQ non-respondents).

As with the AAS, all personnel in each selected PPDS unit were targeted for a group-administrated baseline SAQ and were ordered to report to a group informed consent session similar to the AAS to explain study purposes, procedures, and confidentiality protections, emphasize the voluntary nature of participation, and answer questions. Written informed consent was then obtained. As in the NSS, baseline PPDS respondents were additionally asked for consent to provide blood samples, to link their Army/ DoD administrative records to their survey responses, and to participate in future assessments. Identifying information was collected from consenting respondents separately from the survey and never merged with de-identified survey data. Similar informed consent procedures were used in the post-deployment data collections. These PPDS recruitment, consent, and data protection procedures were approved by the Human Subjects Committees of all collaborating organizations. Sample sizes, response rates, weighting, and design effects are described in a separate report (Kessler et al., 2013).

\section{The Pre-Post Separation Study (PPSS) platform}

We noted earlier in the section on the NSS that between 140,000 and 190,000 new soldiers enter the US Army each year and that roughly half of these new soldiers are in the Regular Army. The other half are in the USAR and USANG. The number of Regular Army soldiers that leave the Army and return to civilian life each year is roughly comparable to the number that joins. The number of active duty soldiers that do not reenlist is likely to increase over the next few years as the Army downsizes due to the ends of the conflicts in Afghanistan and Iraq. Because this downsizing is occurring at a time of economic uncertainty in the civilian economy, the number of soldiers leaving the Army involuntarily (i.e. they want to reenlist but are not given an opportunity to do so) will increase as well. This will doubtlessly add to the stresses known to accompany the transition from military to civilian life (Wolpert, 2000; Hoge, 2010).

The T3 PPDS includes a number of questions about the transition from Army to civilian life, as we expect that as many as 1500 baseline PPDS respondents will have returned to civilian life at the time of the $\mathrm{T} 3$ survey. While few respondents from the NSS will have returned to civilian life by that time, a substantial number of AAS respondents have already done so and this number will increase over time. Concerns exist about the mental health of recently separated veterans (Ilgen et al., 2012; Conner et al., 2013). Indeed, a recent analysis of the US National Health Interview Survey for 1986 to 1994 found that even before the recent rise in the military suicide rate veterans were twice as likely to die by suicide as socio-demographically comparable non-veterans (Kaplan et al., 2007). However, the vast majority of research on the mental health of veterans is based on analyses of Veterans Affairs (VA) treatment samples rather than on more broadly representative prospective epidemiological samples that follow soldiers through the transition from military to civilian life (Rosenheck and Fontana, 2007; Naragon-Gainey et al., 2012). Based on this observation, we included a PrePost Separation Study (PPSS) component in Army STARRS. The PPSS is only included as a pilot during the first Army STARRS funding cycle in light of the fact that the number of AAS, PPDS, and especially NSS study respondents who return to civilian life during the first five years of Army STARRS funding will be comparatively small. The mixedmode web-telephone survey design used in the T3 PPDS post-return survey will be applied in the PPSS. We think of the PPSS as a pilot for a much more ambitious program of long-term follow-up of the full Army STARRS sample in the coming years.

\section{Coordination among component studies}

As noted in the Introduction, the component Army STARRS studies were designed to create a coordinated whole that would facilitate hypothesis generation, nonexperimental hypothesis testing, targeting of interventions designed to provide more definitive experimental tests of hypotheses about modifiable risk and resilience factors, and evaluations of such intervention. The advantages of coordination can be seen clearly in SHOS-A/B. Much previous research has been carried out using the retrospective case-control design to study risk and resilience factors for suicide (Cavanagh et al., 2003; Dumais et al., 2005) and non-fatal suicidal behaviors (Nock et al., 2010; Bridge et al., 2012), and the designs of Army STARRS 
SHOS-A/B are consistent with those previous studies. However, the integration of SHOS-A/B into the larger Army STARRS initiative creates a unique opportunity to address the critical weakness of suboptimal control group selection that has plagued previous case-control studies in this area. Specifically, while it is well known that conclusions about risk and resilience factors depend critically on the control group selected in case-control studies (Schlesselman, 1982) and this sensitivity has been documented in previous analyses of suicide case-control research that varied the control groups (Brent et al., 1988; Brent et al., 1993), previous case-control studies of suicidal behaviors typically used control groups made up of healthy people randomly selected from the general population (but not matched on widely known risk factors such as the presence of a mental disorder) or convenience samples of psychiatric patients selected in an effort to control for the presence of a mental disorder (but not representative of the broader population of those at risk, many of whom commit suicide without ever seeking professional treatment for their emotional problems). As noted in the body of the paper, this weakness was addressed in SHOS-A/B by using propensity score matching methods (Rosenbaum and Rubin, 1983) to select probability samples of soldiers from the AAS as controls with an over-sampling of AAS respondents who reported suicidal ideation. This design refinement, which allows much more sensitive comparisons of cases and controls than in previous case-control studies of suicidal behaviors (Li et al., 2011), would have been impossible in the absence of the HADS and AAS studies being carried out in parallel with SHOS-A/B.

In a similar way, the three large-scale Army STARRS SAQ data collections (NSS, AAS, PPDS) are enriched by being linked with administrative data and blood samples collected by Army phlebotomists. Prospective administrative data are of special importance in this regard, as they are allowing a wide range of analyses to be carried out that would otherwise have been impossible with cross-sectional survey data. For example, prospective administrative data linked to the NSS are currently being used to examine the extent to which an assessment of risk and resilience factors carried out at the very beginning of active duty can pinpoint new soldiers at elevated risk of suicidal behaviors and other serious adverse outcomes (e.g. serious injuries, victimization or perpetration of violent offenses) during the first two years of their Army service.

\section{Discussion}

This report has presented a brief overview of the designs of the component studies within the Army STARRS initiative. While this overview makes it clear that each of these component studies is a substantial undertaking in its own right, it is also important to recognize that all the component studies are strengthened by virtue of their integration with the others. This is true not only in that data elements are shared across component studies but also because the full set of studies taken together allows hypothesis generation and non-experimental testing to be combined with intervention targeting and, in time, intervention evaluation to address the full range of research questions raised in grappling with the problem of Army suicides. While this broad scope and integration do not guarantee that Army STARRS will succeed in achieving its substantive goals, they create a strong foundation for doing so.

\section{Acknowledgments}

On behalf of the Army STARRS Collaborators

\section{Funding/Support}

Army STARRS was sponsored by the Department of the Army and funded under cooperative agreement number U01MH087981 with the US Department of Health and Human Services, National Institutes of Health, National Institute of Mental Health (NIH/NIMH). The contents are solely the responsibility of the authors and do not necessarily represent the views of the Department of Health and Human Services, NIMH, the Department of the Army, or the Department of Defense.

\section{Role of the Sponsors}

As a cooperative agreement, scientists employed by NIMH (Colpe and Schoenbaum) and Army liaisons/consultants (COL Steven Cersovsky, MD, MPH USAPHC and Kenneth Cox, MD, MPH USAPHC) collaborated to develop the study protocol and data collection instruments, supervise data collection, plan and supervise data analyses, interpret results, and prepare reports. Although a draft of this manuscript was submitted to the Army and NIMH for review and comment prior to submission, this was with the understanding that comments would be no more than advisory.

\section{Additional Contributions}

The Army STARRS Team consists of Co-Principal Investigators: Robert J. Ursano, MD (Uniformed Services University of the Health Sciences) and Murray B. Stein, MD, MPH (University of California San Diego and VA San Diego Healthcare System); Site Principal Investigators: Steven Heeringa, PhD (University of Michigan) and Ronald C. Kessler, PhD (Harvard Medical School); NIMH 
collaborating scientists: Lisa J. Colpe, $\mathrm{PhD}, \mathrm{MPH}$ and Michael Schoenbaum, PhD; Army liaisons/consultants: COL Steven Cersovsky, MD, MPH (USAPHC) and Kenneth Cox, MD, MPH (USAPHC). Other team members: Pablo A. Aliaga, MA (Uniformed Services University of the Health Sciences); COL David M. Benedek, MD (Uniformed Services University of the Health Sciences); Susan Borja, PhD (National Institute of Mental Health); Gregory G. Brown, PhD (University of California San Diego); Laura Campbell-Sills, PhD (University of California San Diego); Catherine Dempsey, PhD, MPH (Uniformed Services University of the Health Sciences); Richard Frank, PhD (Harvard Medical School); Carol S. Fullerton, PhD (Uniformed Services University of the Health Sciences); Nancy Gebler, MA (University of Michigan); Joel Gelernter, MD (Yale University); Robert K. Gifford, PhD (Uniformed Services University of the Health Sciences); Stephen E. Gilman, ScD (Harvard School of Public Health); Marjan G. Holloway, PhD (Uniformed Services University of the Health Sciences); Paul E. Hurwitz, MPH (Uniformed Services University of the Health Sciences); Sonia Jain, PhD (University of California San Diego); Tzu-Cheg Kao, PhD (Uniformed Services University of the Health Sciences); Karestan C. Koenen, PhD (Columbia University); Lisa Lewandowski-Romps, $\mathrm{PhD}$ (University of Michigan); Holly Herberman Mash, PhD (Uniformed Services University of the Health Sciences); James E. McCarroll, $\mathrm{PhD}, \mathrm{MPH}$ (Uniformed Services University of the Health Sciences); Katie A. McLaughlin, PhD (Harvard Medical School); James A. Naifeh, PhD (Uniformed Services University of the Health Sciences); Matthew K. Nock, PhD (Harvard University); Rema Raman, PhD (University of California San Diego); Nancy A. Sampson, BA (Harvard Medical School); LCDR Patcho Santiago, MD, MPH
(Uniformed Services University of the Health Sciences); Michaelle Scanlon, MBA (National Institute of Mental Health); Jordan Smoller, MD, ScD (Harvard Medical School); Nadia Solovieff, PhD (Harvard Medical School); Michael L. Thomas, PhD (University of California San Diego); Christina Wassel, PhD (University of Pittsburgh); and Alan M. Zaslavsky, PhD (Harvard Medical School). The authors would also like to thank John Mann, Maria Oquendo, Barbara Stanley, Kelly Posner, and John Keilp for their contributions to the early stages of Army STARRS development.

\section{Additional Information}

A complete list of Army STARRS publications can be found at http://www.ARMYSTARRS.org.

\section{Declaration of interest statement}

In the past five years Kessler has been a consultant for Eli Lilly \& Company, Glaxo, Inc., Integrated Benefits Institute, Ortho-McNeil Janssen Scientific Affairs, Pfizer Inc., Sanofi-Aventis Groupe, Shire US Inc., and Transcept Pharmaceuticals Inc. and has served on advisory boards for Johnson \& Johnson. Kessler has had research support for his epidemiological studies over this time period from Eli Lilly \& Company, EPI-Q, GlaxoSmithKline, OrthoMcNeil Janssen Scientific Affairs, Sanofi-Aventis Groupe, Shire US, Inc., and Walgreens Co. Kessler owns a 25\% share in DataStat, Inc. Stein has in the last three years been a consultant for Healthcare Management Technologies and had research support for pharmacological imaging studies from Janssen. The remaining authors report no competing interests.

\section{References}

Armed Forces Health Surveillance Center (2012) Deaths while on active duty in the U.S. Armed Forces, 1990-2011. Medical Surveillance Monthly Reports, 19(5), 2-5.

Brent D.A., Perper J.A., Goldstein C.E., Kolko D.J., Allan M.J., Allman C.J., Zelenak J.P. (1988) Risk factors for adolescent suicide. A comparison of adolescent suicide victims with suicidal inpatients. Archives of General Psychiatry, 45(6), 581-588.

Brent D.A., Perper J.A., Moritz G., Allman C., Friend A., Roth C., Schweers J., Balach L., Baugher M. (1993) Psychiatric risk factors for adolescent suicide: a case-control study. Journal of the American Academy of Child and
Adolescent Psychiatry, 32(3), 521-529, DOI: 10.1097/00004583-199305000-00006

Bridge J.A., McBee-Strayer S.M., Cannon E.A., Sheftall A.H., Reynolds B., Campo J.V., Pajer K.A., Barbe R.P., Brent D.A. (2012) Impaired decision making in adolescent suicide attempters. Journal of the American Academy of Child and Adolescent Psychiatry, 51(4), 394-403, DOI: 10.1016/j.jaac.2012.01.002

Cavanagh J.T., Carson A.J., Sharpe M., Lawrie S.M. (2003) Psychological autopsy studies of suicide: a systematic review. Psychological Medicine, 33(3), 395-405, DOI: 10.1017/S0033291702006943

Centers for Disease Control (2005) CDC Reports Latest Data on Suicide Behaviors, Risk Factors, and Prevention, Atlanta, GA, Centers for Disease Control.

Committee on Youth, Population and Military Recruitment: Physical, Medical, and Mental Health Standards, National Research Council (2006) Assessing Fitness for Military Enlistment: Physical, Medical, and Mental Health Standards, Washington: DC, National Academy Press.

Conner K.R., Bohnert A.S., McCarthy J.F., Valenstein M., Bossarte R., Ignacio R., Lu N., Ilgen M.A. (2013) Mental disorder comorbidity and suicide among 2.96 million men receiving care in the veterans health administration health system. Journal of Abnormal Psychology, 122(1), 256-263, DOI: 10.1037/a0030163 
Dumais A., Lesage A.D., Alda M., Rouleau G. Dumont M., Chawky N., Roy M., Mann J.J., Benkelfat C., Turecki G. (2005) Risk factors for suicide completion in major depression: a case-control study of impulsive and aggressive behaviors in men. American Journal of Psychiatry, 162(11), 2116-2124, DOI: 10.1176/appi.ajp.162.11.2116

Goldsmith S.K., Pellmar T.C., Kleinman A.M., Bunney W.E. eds. (2002) Reducing Suicide A National Imperative, Washington: DC, National Academy Press.

Hoge C.W. (2010) Once a Warrior Always a Warrior: Navigating the Transition from Combat to Home, Including Combat Stress, PTSD, and mTBI, Guilford, CT: Globe Pequot Press.

Ilgen M.A., McCarthy J.F., Ignacio R.V., Bohnert A.S., Valenstein M., Blow F.C., Katz I.R. (2012) Psychopathology, Iraq and Afghanistan service, and suicide among Veterans Health Administration patients. Journal of Consulting and Clinical Psychology, 80(3), 323-330, DOI: 10.1037/a0028266

Insel T.R. McHugh J.M. (submitted for publication) The U.S. Army-National Institute of Mental Health Army Study to Assess the Risk and Resilience in Servicemembers (Army STARRS): rapidly translating interventions to reduce suicide.
Kaplan M.S., Huguet N., McFarland B.H., Newsom J.T. (2007) Suicide among male veterans: a prospective population-based study. Journal of Epidemiology and Community Health, 61(7), 619-624, DOI: 10.1136/jech.2006.054346

Kessler R.C., Heeringa S.G., Colpe L.J., Fullerton C. S., Gebler N., Hwang, I., Naifeh J.A., Nock M. K., Sampson N.A., Schoenbaum M., Zaslavsky A.M., Stein M.B., Ursano R.J. (2013) Response bias, weighting adjustments, and design effects in the Army Study to Assess Risk and Resilience in Servicemembers (Army STARRS). International Journal of Methods in Psychiatric Research, 22(4), 288-302.

Kuehn B.M. (2009) Soldier suicide rates continue to rise: military, scientists work to stem the tide. Journal of the American Medical Association, 301(11), 1111-1113, DOI: $10.1001 /$ jama.2009.342

Li L., Shen C., Wu A.C., Li X. (2011) Propensity score-based sensitivity analysis method for uncontrolled confounding. American Journal of Epidemiology, 174(3), 345-353, DOI: 10.1093/aje/kwr096

Naragon-Gainey K., Hoerster K.D., Malte C.A., Jakupcak M. (2012) Distress symptoms and high-risk behaviors prospectively associated with treatment use among returning veterans. Psychiatric Services, 63(9), 942-944, DOI: 10.1176/appi.ps.201100349
Nock M.K., Park J.M., Finn C.T., Deliberto T.L., Dour H.J., Banaji M.R. (2010) Measuring the suicidal mind: implicit cognition predicts suicidal behavior. Psychological Science, 21(4), 511-517, DOI: 10.1177/0956797610364762

Rosenbaum P.R., Rubin D.B. (1983) The central role of the propensity score in observational studies for causal effects. Biometrika, 70(1), 41-55.

Rosenheck R.A., Fontana A.F. (2007) Recent trends In VA treatment of post-traumatic stress disorder and other mental disorders. Health Affairs (Millwood), 26(6), 1720-1727, DOI: 10.1377/ hlthaff.26.6.1720

Schlesselman J.J. (1982) Case-control Studies: Design, Conduct, Analysis, New York: Oxford University Press.

Singer J.D., Willett J.B. (2003) Applied Longitudinal Data Analysis: Modeling Change and Event Occurrence, New York: Oxford University Press.

Strauss A.L. (1987) Qualitative Analysis for Social Scientists, Cambridge: Cambridge University Press.

Wolpert D.S. (2000) Military retirement and the transition to civilian life. In Martin J. A., Rosen L.N., Sparacino L.R. (eds) The Military Family: A Practice Guide for Human Services Providers, pp 103-119, New York, Praeger. 